\title{
Activation of distractor names in the picture-picture interference paradigm
}

\author{
ANTJE S. MeYer \\ University of Birmingham, Birmingham, England \\ AND \\ MARKus F. DAMian \\ University of Bristol, Bristol, England
}

\begin{abstract}
In four experiments, participants named target pictures that were accompanied by distractor pictures with phonologically related or unrelated names. Across experiments, the type of phonological relationship between the targets and the related distractors was varied: They were homophones (e.g., bat [animal/baseball]), or they shared word-initial segments (e.g., dog-doll) or word-final segments (e.g., ball-wall). The participants either named the objects after an extensive familiarization and practice phase or without any familiarization or practice. In all of the experiments, the mean target-naming latency was shorter in the related than in the unrelated condition, demonstrating that the phonological form of the name of the distractor picture became activated. These results are best explained within a cascaded model of lexical access - that is, under the assumption that the recognition of an object leads to the activation of its name.
\end{abstract}

In order to produce a word, in isolation or as part of a longer utterance, speakers must select a concept to be referred to and retrieve the corresponding lexical information from the mental lexicon. Lexical access - the retrieval of a word from the mental lexicon-is commonly viewed as consisting of two main components: First, speakers select a word unit (sometimes called a lemma; see, e.g., Levelt, 1989) and then they retrieve the associated word form-that is, the morphological, phonological, and phonetic information (see, e.g., Butterworth, 1989; Garrett, 1980; Levelt, 1989). Evidence for the distinction between lexical selection and word form retrieval comes from a variety of sources, including, for instance, the occurrence of tip-of-the-tongue states, in which speakers have a strong feeling of knowing a word, have access to its meaning and syntactic properties (e.g., its grammatical gender), but cannot retrieve the complete phonological form (see, e.g., Brown \& McNeill, 1966; Vigliocco, Antonini, \& Garrett, 1997; for reviews, see Levelt, 1999; Levelt, Roelofs, \& Meyer, 1999; Rapp \& Goldrick, 2000).

A much debated question concerns the information flow during word planning. According to serial stage models of lexical access, word planning consists of a set of stages, which are completed in a specific order. This view entails that a late processing stage commences only after the preceding stage has been completed and has delivered its output (see, e.g., Bloem \& La Heij, 2003; Levelt, 1989; Levelt et al., 1999; Roelofs, 1992, 1997). An alternative position, endorsed by cascaded models of lexical access, is that word planning consists of processing steps that are temporally ordered but may overlap in time (Caramazza, 1997; Dell, 1986; Dell, Burger, \& Svec, 1997; Humphreys, Riddoch, \& Quinlan, 1988; MacKay, 1987; Stemberger, 1985). The theoretical importance of this question derives from its link to the general modularity debate within psychology and cognitive science (Fodor, 1983) — that is, the question whether complex cognitive processes should be viewed as sets of independent modules, and if this is so, how the modules should be defined.

Much of the empirical work on the information flow during lexical access has concerned the conditions for the activation of word form information. The basic question is this: Does every concept that is activated in a speaker's mind automatically activate the corresponding name in the mental lexicon (provided that a name exists), or is name activation restricted in some way? When speakers want to refer to an object (e.g., a car), they need to decide what to call it. During this process, several concepts (e.g., car, limousine, taxi) may become activated, and the speaker must select the most suitable one (see, e.g., Dell, 1986; Levelt, 1989). According to cascaded models of lexical access, each of these candidate concepts sends some activation to the associated lexical units and word forms. By contrast, in serial stage models, word form access is restricted to selected units. In the model proposed by Levelt et al. (1999), activation spreads bidirectionally between concepts and lemmas, which, in that model, are semantically and syntactically specified word units. Eventually, a lemma is se-

A. S. Meyer, a.s.meyer@bham.ac.uk 
lected to be part of the utterance, and only then is word form information retrieved, for the selected lemma only. According to the serial stage model proposed by Bloem and La Heij (2003; Bloem, van den Boogard, \& La Heij, 2004), the speaker first selects a single concept, and only then does activation spread to the associated lemma and word form. Thus, in both serial stage models, word form access is restricted to those units that the speaker intends to include in the utterance.

Researchers have used a variety of paradigms and techniques to decide between cascaded and serial stage models (for recent reviews, see also Morsella \& Miozzo, 2002; Navarrete \& Costa, 2005). Several studies have investigated whether the phonological forms of semantically related competitors become activated when speakers prepare to say a target word, as would be predicted by cascaded models. In analyses of speech errors, Dell and Reich (1981) found that speakers committed "mixed" errors, in which target and error were related in form and meaning (e.g., saying "rat" instead of "cat"), more frequently than would be predicted on the basis of the rates of pure semantic errors (saying "dog" instead of "cat") and pure phonological errors (saying "mat" instead of "cat"; see also Ferreira \& Griffin, 2003). This is predicted by cascaded models, but not by serial stage models. However, serial stage models can account for this finding as well under the assumption that speakers are less likely to detect and correct errors in their speech plans when the incorrect words are similar to the targets in form, as well as meaning, than when they are similar to the targets in only one respect.

Peterson and Savoy (1998; see also Jescheniak \& Schriefers, 1998) asked participants to name objects that had a dominant name (e.g., sofa) and a plausible nearsynonymous alternative name (e.g., couch). On some of the trials, a written word was shown shortly after picture onset, which the participants had to name instead of the picture. The mean word-naming latency was shorter when the probe was related to the dominant or to the alternative name of the target than when it was unrelated to both, demonstrating that both names became activated when participants prepared to name the objects. By contrast, this and several other studies (e.g., Jescheniak, Hahne, \& Schriefers, 2003; Levelt et al., 1991) showed that the forms of more distantly related competitors to a target (e.g., the form of the competitor cat for the target $\mathrm{dog}$ ) did not become activated. These findings can be viewed as supporting cascaded models: Competitors to a target activate the forms of their names, but this activation is only strong enough to be measured in a probe paradigm when target and competitor are very close in meaning - that is, when they are near-synonyms. However, the serial stage model proposed by Bloem and La Heij (2003) can account for these findings as well. In this model, speakers select only one concept, which activates the associated lemma, but then activation spreads from this lemma to semantically related lemmas and their forms. Levelt et al. (1999) also offered an account for these findings within their serial stage model: They proposed that the simultaneous activation of several word forms is seen only in exceptional cases - namely, when speakers fail to select one of two closely related concepts and retrieve the forms of both names (e.g., sofa and couch) in parallel. In short, all models can explain the occasional activation of the phonological form of a semantically related competitor to a target.

La Heij and colleagues (Bloem \& La Heij, 2003; Bloem et al., 2004; La Heij, Hooglander, Kerling, \& van der Velden, 1996) asked participants to translate visually presented English words into Dutch, their native language. The English prompts were presented together with distractor pictures that were members of the same semantic category as the targets or were phonologically related or unrelated to the Dutch response words. The semantically related distractor pictures yielded facilitation in comparison with unrelated pictures (i.e., shorter translation latencies), whereas the phonologically related distractors yielded no effect. La Heij and colleagues concluded that the semantic effect arose at the conceptual level, when the participants decided for which concept a Dutch name had to be found, and that the distractor names were not activated, as their serial stage model of lexical access predicts.

However, conflicting evidence comes from a picturepicture interference study by Morsella and Miozzo (2002). They showed English speakers stimuli consisting of two superimposed line drawings of objects, one red and one green. The speakers had to name the green target objects only. Morsella and Miozzo found faster target-naming latencies when the names of target and distractor were phonologically related (e.g., bell-bed) than when they were unrelated (bell-hat). Apparently, the name of the distractor became activated and the phonological form of the target name could be retrieved faster when it was related than when it was unrelated to the distractor. Navarrete and Costa (2005) recently replicated the phonological relatedness effect observed by Morsella and Miozzo in a very similar experiment carried out with speakers of Spanish. These results offer strong support for cascaded models of word production.

One goal of the present study was to determine whether we could obtain a phonological relatedness effect in a picture-picture interference experiment as well. When the study was planned, the effect had only been seen in Morsella and Miozzo's (2002) experiment, whereas in the experiments by La Heij and colleagues, which used the closely related translation paradigm, the effect had been consistently absent. Given the theoretical importance of the phonological relatedness effect as an indicator of cascaded processing, a replication seemed desirable.

The materials of Experiment 1 were selected with the aim of maximizing the chances of obtaining a phonological relatedness effect. We used pairs of objects with homophonous names, such as bat (animal/baseball) and boy-buoy. The names of these objects were semantically unrelated, but they shared all phonological segments and, on some theories, the morphological representation (e.g., Jescheniak \& Levelt, 1994; Jescheniak, Meyer, \& Levelt, 2003; but see Caramazza, Bi, Costa, \& Miozzo, 2004; Caramazza, Costa, Miozzo, \& Bi, 2001; Miozzo, Jacobs, \& Singer, 2004). If the distractor name becomes activated while participants are preparing to name the target, the target-naming latencies should be shorter when 
the distractor and the target are homophones and activate the same set of segments and possibly the same morphological representation than when they are unrelated. Homophonous target-distractor pairs had not been used in Morsella and Miozzo's (2002) or Navarrete and Costa's (2005) experiments.

Experiment 2 used two types of target-distractor pairs with phonologically related names - namely, beginrelated pairs, such as bed-bell, and end-related pairs, such as ball-wall. The goal was to determine whether the phonological relatedness effect could be seen for different sets of materials and different types of phonological relatedness. This extends the studies by Morsella and Miozzo (2002) and by Navarrete and Costa (2005) who used begin-related pairs only.

In some word-production paradigms, begin-related as well as end-related primes or distractors facilitate the production of target words. This is, for instance, the case for the picture-word interference paradigm, in which participants name target objects that are presented together with phonologically related or unrelated distractor words (Collins \& Ellis, 1992; Meyer \& Schriefers, 1991; see also Damian \& Martin, 1999; Schriefers, Meyer, \& Levelt, 1990; Wilshire \& Saffran, 2005). By contrast, in other paradigms, the effects of begin- and end-related stimuli are different. This is the case for response-preparation paradigms in which participants, rather than naming targets and ignoring distractors, produce several related or unrelated words in succession. The most common finding is that begin-relatedness between responses yields facilitation, whereas end-relatedness has no effect relative to an unrelated control condition (Cholin, Schiller, \& Levelt, 2004; Meyer, 1990, 1991; Roelofs, 2002, 2004; but see Sevald \& Dell, 1994). This pattern can be accounted for by assuming that speakers activate the phonological segments of a word in parallel, but select the articulatory commands in sequence, progressing from the beginning to the end of a word (for further discussion, see Meyer \& Belke, in press; Roelofs, 2004). Similar effects of begin- and end-related distractors arise when the distractors activate some of the segments of the target words, but speakers do not prepare to articulate the distractor names. By contrast, facilitation is confined to begin-related stimuli when speakers prepare for the articulation of two or more related or unrelated words. Thus, a comparison of the effects of begin-related and end-related distractors in the picture-picture interference paradigm might yield some information about the origin of the relatedness effect.

Finally, the present study aimed to clarify an important methodological issue: It is standard practice in picturenaming experiments in which naming latencies are the most important dependent variable to familiarize the participants with the pictures and their names before the main experiment and to include a practice block, in which the participants name all of the pictures, and naming errors are corrected. Familiarization and practice are considered necessary measures to keep data loss due to naming errors and hesitations at an acceptably low level. During the main experiment, the targets are usually presented several times, typically in combination with different distractors.
Item repetition is often necessary because the set of suitable pictures is small. In addition, it allows researchers to rule out that differences between the experimental conditions arise because of incidental differences between the sets of materials used. Morsella and Miozzo (2002) and Navarrete and Costa (2005) familiarized the participants with the materials, included a practice block, and repeated the items during the experiment. The same was done in three of the present experiments. However, it is possible that these measures create effects that would not otherwise be observed. For instance, in the picture-picture interference paradigm, a phonological relatedness effect might only occur when the participants are highly familiar with materials, so that the names of the distractors become rapidly activated. We assessed this hypothesis by examining whether the size of the phonological relatedness effect developed systematically during the course of the experiment and by conducting a pair of experiments (Experiments $2 \mathrm{~A}$ and 3 ) that differed only in the presence or absence of a familiarization and practice phase.

\section{EXPERIMENT 1}

\section{Method}

Participants. The participants in all of the experiments were undergraduate students of the University of Birmingham. They were native speakers of British English and reported having normal or corrected-to-normal vision. They received course credits or payment in return for their time. Each participant took part in only one of the experiments reported here. Experiment 1 was carried out with 18 participants.

Materials. The materials consisted of 42 line drawings of common objects. ${ }^{1}$ They were selected from the Snodgrass and Vanderwart (1980) picture set or a picture database provided by the Max Planck Institute for Psycholinguistics (Nijmegen, The Netherlands). The materials included 14 pairs of objects with homophonous names, such as bat and tank, which had also been used in a study by Morgan and Meyer (2005). These items were used on experimental trials. The remaining 14 pictures were used on practice trials only.

The targets were shown as green line drawings and the distractors as superimposed red line drawings, as in Morsella and Miozzo's (2002) experiments. The pictures fitted into squares of approximately $9 \mathrm{~cm}$ on each side ( $8.5^{\circ}$ of visual angle) and were shown in the center of the screen on a light gray background.

Design. The experiment included three experimental conditions. In the homophone condition, the two members of a homophonous pair were shown together. Each object appeared as a target (in green) and, on a different trial, as a distractor (in red). Therefore, the 14 homophonous pairs yielded 28 target-distractor pairs with homophonous names. For the unrelated condition, targets and distractors were recombined into phonologically and semantically unrelated pairs. For instance, the target bat (animal) was shown with the distractor nut (walnut), and the target bow (ribbon) with the distractor pipe (drainage). In the third condition, the targets were presented without distractors. The target-naming latencies were expected to be much shorter in this condition than in the unrelated and related distractor condition, mainly because the targets should be much easier to identify when presented without superimposed distractors. In a companion series of experiments, the distractors were presented in a different format, nested inside the targets, as in Damian and Bowers's (2003) study. The inclusion of the no-distractor condition in both sets of experiments allowed us to test whether superimposed distractors interfered more strongly with target naming than did nested ones.

The experiment included two practice blocks and six experimental blocks. In each block, each target was shown once. In the 
Table 1

Results of Experiment 1: Mean Object-Naming Latencies (in Milliseconds) and Error Rates (\%) per Condition

\begin{tabular}{lccc}
\hline \multirow{2}{*}{\multicolumn{1}{c}{ Condition }} & \multicolumn{2}{c}{ Naming Latency } & \\
\cline { 2 - 4 } & $M$ & $S E$ & Error Rate \\
\hline No distractor & 651 & 17 & 0.1 \\
Homophonous distractor & 718 & 20 & 0.3 \\
Unrelated distractor & 757 & 22 & 1.4 \\
\hline
\end{tabular}

first practice block, the participants named the 42 line drawings individually - that is, without distractors. In the second practice block, each experimental item was shown together with one of the unrelated practice distractors mentioned above. The participants named the targets. Any naming errors occurring in these blocks were corrected by the experimenter in the following pause. The naming latencies from the practice blocks were not analyzed.

In each of the following six experimental blocks, each target was shown once. In each block, 9 or 10 targets were presented in each of the three experimental conditions. Each target was tested in a different condition in each of the first three blocks. Blocks 4, 5, and 6 repeated the materials of Blocks 1,2, and 3, respectively. By the end of the experiment, each participant had named each target eight times, twice in the practice blocks and six times in the experimental blocks (twice in each condition). Three different orders of the experimental blocks were used, each for 6 participants. The order of the items within a block was random and different for each participant.

Apparatus. In all of the experiments, the software package NESU (Nijmegen Experimental Setup, Max Planck Institute for Psycholinguistics, Nijmegen, The Netherlands) was used to display the stimuli and record the speech onset latencies. The stimuli were presented on a 19-in. Samtron 95P Plus color monitor. The participants' speech was recorded using a Sony microphone and a Sony DAT recorder. Speech onset latencies were measured using a voice key (HASOMED GmbH, Magdeburg, Germany).

Procedure. The participants were tested individually in a quiet room. They first saw a booklet, which displayed all of the pictures used in the experiment and their names. They were asked to familiarize themselves with the materials and to use only the names given in the booklet during the experiment. The practice blocks and the six experimental blocks followed. There were brief pauses between blocks.

All of the trials had the same structure. At the beginning of a trial, a fixation mark (a cross) was shown for $500 \mathrm{msec}$, followed first by a blank interval of $200 \mathrm{msec}$ and then by a single object or a target-distractor composite. The stimulus remained in view until the voice key was triggered or for maximally $2 \mathrm{sec} .850 \mathrm{msec}$ after picture offset, the next trial began with the presentation of a fixation mark. This procedure was used in all of the experiments.

\section{Results and Discussion}

The results are summarized in Table 1. The rate of naming errors - that is, trials on which participants used object names other than the expected ones - was low $(0.6 \%$ of the trials), most likely because of the extensive practice preceding the main experiment. In the unrelated condition, participants occasionally (on 11 out of 15 error trials in this condition) named the distractor instead of the target. Such errors could not be observed in the homophone condition, in which the names of the target and distractor were identical.

Errors were excluded from the analysis of the speech onset latencies. In addition, we excluded $4.7 \%$ of the trials as spoiled trials because the voice key was triggered too early by external noise or nonspeech sounds produced by the participant. We also excluded all latencies exceeding $2,000 \mathrm{msec}(0.1 \%$ of the trials), and all latencies deviating from a participant's condition mean by more than $3 S D$ s ( $1.7 \%$ of the trials). Similar criteria for the exclusion of latencies were used by Morsella and Miozzo (2002) and Damian and Bowers (2003; see also Ratcliff, 1993; Van Selst \& Jolicœur, 1994, for a discussion of strategies for dealing with reaction time outliers).

The mean speech onset latency was shortest in the nodistractor condition, intermediate in the homophone condition, and longest in the unrelated condition. The main effect of condition was significant $\left[F_{1}(2,34)=96.78\right.$, $M S_{\mathrm{e}}=537 ; F_{2}(2,54)=52.12, M S_{\mathrm{e}}=1,553$, both $p \mathrm{~s}<$ $.001]$. Planned comparisons showed that the 106-msec difference between the no-distractor and the unrelated condition was significant $\left[t_{1}(17)=11.12 ; t_{2}(27)=8.38\right.$, both $p \mathrm{~s}<.001$ ], as was the 39-msec difference between the unrelated and the homophone condition $\left[t_{1}(17)=4.93\right.$; $\left.t_{2}(27)=2.87, p<.01\right]$. In other words, the homophonous distractors facilitated target naming in comparison with the unrelated ones. This implies that the distractor name became activated while the target name was being prepared. As explained above, the facilitatory effect most likely arose because in homophonous pairs, target and distractor activated the same set of segments and possibly the same morphological representation.

The participants saw each target six times, once in each of the six test blocks. We examined whether the latency differences between the experimental conditions systematically changed over the six repetitions of the materials. One might expect the facilitatory effect of homophonous distractors to increase as the materials became more familiar and the object names became more readily accessible. However, Figure 1 shows that there was no systematic development of the differences between the conditions across the blocks. In a by-participant analysis including block as a variable, we obtained a significant main effect of distractor condition $\left[F(2,34)=96.21, M S_{\mathrm{e}}=3,266\right.$, $p<.001]$ and a significant interaction of block and condition $\left[F(10,170)=1.89, M S_{\mathrm{e}}=1,520, p=.05\right]$, which was due to the variability of the effect sizes across blocks. This variability probably arose because, in each block, only 9 or 10 items were tested in each condition, and within a block, different items were tested in each condition. ${ }^{2}$ Planned comparisons showed that the difference between the no-distractor and the unrelated condition was highly significant $(p<.001)$ in each block, though it varied in magnitude between $78 \mathrm{msec}$ (Block 3) and $123 \mathrm{msec}$ (Block 5). The difference between the homophone and the unrelated condition was significant $(p<.01)$ in five of the six blocks, and ranged from 37 msec (Block 2) to $60 \mathrm{msec}$ (Block 4). In sum, there was no evidence that the strength of the relatedness effect systematically increased or decreased over the course of the experiment.

\section{EXPERIMENT 2}

Experiment 1 yielded a strong phonological relatedness effect. When the target and distractor picture had the same name, the mean target-naming latency was shorter than when they had unrelated names. As explained in the introduction, the goal of Experiment 2 was to determine 


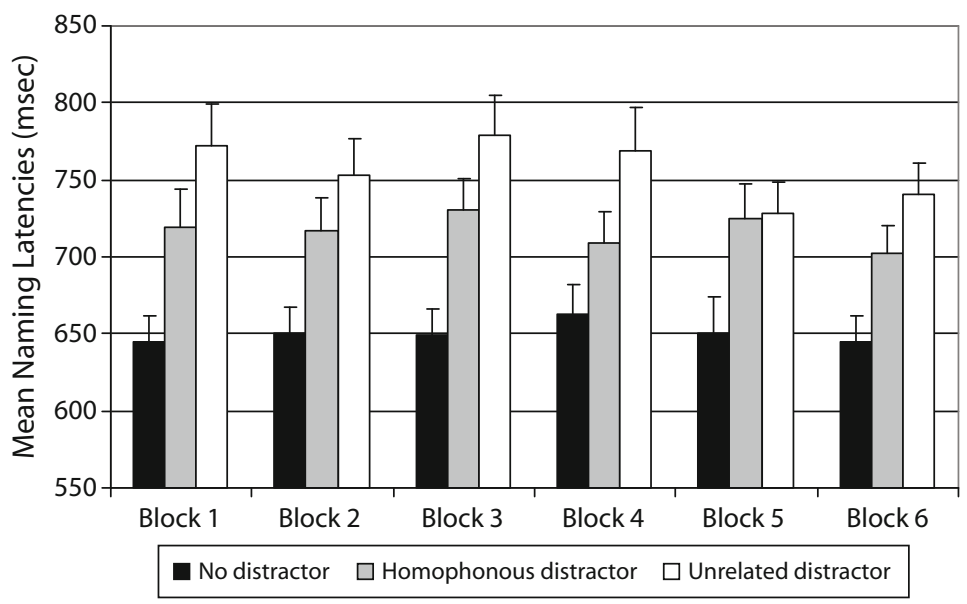

Figure 1: Mean naming latencies for the three distractor conditions and each block of Experiment 1. Error bars indicate standard errors of participant means.

whether a phonological relatedness effect would also be obtained when the targets and related distractors had similar, rather than identical, names. In Experiment 2A, the participants saw object pairs with begin-related or unrelated names, and in Experiment 2B, they saw object pairs with end-related or unrelated names.

\section{Method}

Participants. Experiments 2A and 2B were carried out with 12 participants each.

Materials. For Experiment 2A, 30 pairs of objects with beginrelated names were selected from the same picture database as were the stimuli of Experiment 1. In 8 pairs, both names were disyllabic (e.g., package-parrot, rabbit-radish) and in the remaining pairs, they were both monosyllabic (e.g., pig-pin, cloud-clown). The members of a pair shared at least the onset consonant or consonant cluster and the following vowel. For Experiment 2B, 30 pairs of objects with monosyllabic rhyming names (e.g., mat-bat, horn-corn) were selected. The object names shared the vowel and the following consonant or consonant cluster. Each object was used as a target and as a distractor. Sixty-six additional objects were used during practice and warm-up trials.

Design. The experiments included three experimental conditions. In the phonologically related condition, the members of the object pairs described above were shown together. In the unrelated condition, targets and distractors were recombined into phonologically and semantically unrelated pairs. As in Experiment 1, there was also a no-distractor condition.

There were two practice blocks and six experimental blocks. In the first practice block, the participants named all of the line drawings without distractors. In the second practice block, they named the targets shown together with unrelated practice distractors. Each of the following experimental blocks included 32 trials ( 2 warm-up trials followed by 30 experimental trials). Each target was shown three times, once in each condition, either in Blocks 1, 3, and 5 or in Blocks 2, 4, and 6. Within a block, each object appeared only once as a target, but it could appear once or twice as a distractor as well. Across the entire experiment, each object appeared twice during the practice blocks and three times as a target and twice as a distractor in experimental blocks. Three different orders of the experimental blocks were created, each of which was used for testing 4 participants. The order of the trials within blocks was random and different for each participant.

Procedure. The procedure was the same as in Experiment 1.

\section{Results and Discussion}

Experiment 2A. As in Experiment 1, the error rate was low $(0.8 \%$; see Table 2$)$. Errors were excluded from the analyses of speech onset latencies, as were spoiled trials (3.8\% of the trials), latencies exceeding $2,000 \mathrm{msec}(0.1 \%$ of the trials), and latencies deviating from a participant's condition mean by more than $3 S D \mathrm{~s}$ ( $1.7 \%$ of the trials).

The mean target-naming latency was shortest in the no-distractor condition, intermediate in the begin-related condition, and longest in the unrelated condition (see Table 2A). The main effect of condition was significant $\left[F_{1}(2,22)=95.33, M S_{\mathrm{e}}=373 ; F_{2}(2,118)=82.27\right.$, $M S_{\mathrm{e}}=2,223$, both $\left.p \mathrm{~s}<.001\right]$. The 23-msec difference between the begin-related and unrelated condition was likewise significant $\left[t_{1}(11)=4.00 ; t_{2}(59)=2.73\right.$, both $p \mathrm{~s}<.01]$. Thus, the begin-related distractors, like the homophonous ones used in Experiment 1, facilitated target naming in comparison with the unrelated distractors. The 104-msec difference between the unrelated and the nodistractor condition was also significant $\left[t_{1}(11)=9.28\right.$; $t_{2}(59)=10.37$, both $p$ s $\left.<.001\right]$.

In this experiment, each participant saw each target three times, either in Blocks 1, 3, and 5 or in Blocks 2, 4 , and 6 . An analysis including the three presentations of the materials as a variable yielded only a main effect of

Table 2

Results of Experiment 2: Mean Object-Naming Latencies (in Milliseconds) and Error Rates (\%) per Condition

\begin{tabular}{lllc}
\hline & \multicolumn{2}{c}{ Latency } & \\
\cline { 2 - 3 } \multicolumn{1}{c}{ Condition } & $M$ & $S E$ & Error Rate \\
\hline Experiment 2A & & & \\
$\quad$ No distractor & 635 & 21 & 0.7 \\
$\quad$ Begin-related distractor & 716 & 20 & 0.8 \\
$\quad$ Unrelated distractor & 739 & 18 & 0.8 \\
Experiment 2B & & & \\
$\quad$ No distractor & 671 & 18 & 0.8 \\
$\quad$ End-related distractor & 767 & 22 & 0.8 \\
$\quad$ Unrelated distractor & 788 & 23 & 1.1 \\
\hline
\end{tabular}


distractor condition $\left[F(2,22)=96.52, M S_{\mathrm{e}}=1,678, p<\right.$ $.01]$, but no main effect of presentation and no interaction of presentation and distractor condition. The latency difference between the begin-related and unrelated conditions was $38 \mathrm{msec}$ for the first presentation of the targets $[t(11)=3.47, p<.01]$, a mere $3 \mathrm{msec}$ for the second presentation, and $28 \mathrm{msec}[t(11)=3.87, p<.01]$ for the third presentation.

Experiment 2B. In Experiment 2B, the targets and distractors in the related condition shared word-final segments. Naming errors occurred on $0.9 \%$ of the trials (see Table 2). These trials were excluded from the analyses of naming latencies. In addition, we excluded $1.0 \%$ of the trials as spoiled trials, $0.1 \%$ because the latency exceeded $2,000 \mathrm{msec}$, and $1.8 \%$ because the latencies deviated by more than $3 S D$ s from a participant's condition mean.

For the remaining naming latencies, a significant main effect of distractor condition was obtained $\left[F_{1}(2,22)=\right.$ $78.40, M S_{\mathrm{e}}=593 ; F_{2}(2,118)=132.34, M S_{\mathrm{e}}=1,724$, both $p \mathrm{~s}<.001]$. Again, the mean naming latency was shortest in the no-distractor and longest in the unrelated condition. The 21-msec difference between the end-related and the unrelated condition was significant $\left[t_{1}(11)=3.64, p<\right.$ $\left..01 ; t_{2}(59)=2.32, p<.05\right]$, as was the $117-\mathrm{msec}$ difference between the unrelated and the no-distractor condition $\left[t_{1}(11)=9.22, p<.01 ; t_{2}(59)=12.45, p<.01\right]$.

The analysis including the three presentations of the materials as a variable yielded only a main effect of distractor condition $\left[F(2,22)=78.01, M S_{\mathrm{e}}=1,775, p<\right.$ $.01]$. The facilitatory effect of end-related relative to unrelated distractors was $11 \mathrm{msec}$ for the first presentation, and not significant. For the second and third presentations of the materials, significant effects of $29 \mathrm{msec}[t(11)=$ $3.22, p<.01]$ and $26 \mathrm{msec}[t(11)=2.68, p<.05]$ were obtained.

In sum, the two subexperiments of Experiment 2 yielded very similar results: The target-naming latency was substantially shorter, by $81 \mathrm{msec}$ in Experiment $2 \mathrm{~A}$ and by $96 \mathrm{msec}$ in Experiment 2B, in the no-distractor condition than in the unrelated condition. More importantly, there was a facilitatory effect, of $23 \mathrm{msec}$ in Experiment $2 \mathrm{~A}$ and of $21 \mathrm{msec}$ in Experiment 2B, in the phonologically related in comparison with the unrelated condition. The fact that this effect was obtained for different sets of materials is of some methodological importance because it makes it highly unlikely that the latency difference between the related and unrelated conditions was due to confounding nonphonological variables, such as accidental differences in the visual complexity of the picture combinations.

\section{EXPERIMENT 3}

There was no evidence in Experiments 1 or 2 suggesting that the relatedness effect systematically increased or decreased in size over the repetitions of the materials. However, in both experiments, the participants were thoroughly familiarized with the materials before the experiment proper. The goal of Experiment 3 was to determine whether the phonological relatedness effect would also be obtained when there was no familiarization or practice phase, and to examine whether the size of the effect would change as the participants became more familiar with the materials.

\section{Method}

Participants. There were 18 participants.

Materials and Design. The same experimental items-30 object pairs with begin-related names - were used as in Experiment 2A. The experimental design was identical as well, except that the practice blocks and the warm-up trials of Experiment 2 were omitted.

Procedure. During the main experiment, the same procedure was used as in Experiment 2. However, the participants did not see a booklet showing the objects and their names before the experiment. Instead, they were asked to name the target objects using the first name that came to mind.

\section{Results and Discussion}

The error rate ( $9.3 \%$ of the responses) was much higher than in Experiment 2A (0.9\%, see Tables 2 and 3), in which the same materials had been used. There were also more spoiled trials: $13.6 \%$, in comparison with $3.8 \%$ in Experiment 2A. In almost all of these cases, participants produced hesitations or filled pauses (e.g., "uhm") before naming a picture. Thus, without familiarization and practice, the participants named fewer of the objects correctly and fluently, which is, of course, hardly surprising. ANOVAs showed that the rates of naming errors or the rates of spoiled trials did not differ significantly across the experimental conditions of Experiment 3. In addition to error and spoiled trials, $2.7 \%$ of the trials were excluded from the latency analyses because the latencies exceeded $2,000 \mathrm{msec}$, and $0.9 \%$ of the trials because the latencies deviated from the participant's condition mean by more than $3 S D$ s.

For the remaining latencies, the results were similar to those of Experiment 2A: There was again a significant main effect of condition $\left[F_{1}(2,34)=72.58, M S_{\mathrm{e}}=478\right.$; $F_{2}(2,118)=20.77, M S_{\mathrm{e}}=5,316$, both $\left.p \mathrm{~s}<.001\right]$. The mean latency was significantly shorter, by $86 \mathrm{msec}$, in the no-distractor than in the unrelated condition $\left[t_{1}(11)=\right.$ $11.48 ; t_{2}(59)=6.12$, both $\left.p \mathrm{~s}<.001\right]$. More importantly, the mean naming latency was shorter, by $29 \mathrm{msec}$, in the begin-related than in the unrelated condition. Numerically, this relatedness effect was slightly larger than in Experiment 2A $(21 \mathrm{msec})$, but it reached significance in the analysis by participants only $\left[t_{1}(11)=5.48, p<.01\right.$; $\left.t_{2}(59)=1.39\right]$. This was due to the fact that the betweenitems variability in the latencies was higher in Experiment 3 than in Experiment 2A (mean by-items standard error per condition: $11 \mathrm{msec}$ vs. $8 \mathrm{msec}$ ), which, in turn, was related to the low rate of valid observations for some

Table 3

Results of Experiment 3: Mean Object-Naming Latencies (in Milliseconds) and Error Rates (\%) per Condition

\begin{tabular}{lccc}
\hline \multirow{2}{*}{\multicolumn{1}{c}{ Condition }} & \multicolumn{2}{c}{ Latency } & \\
\cline { 2 - 3 } & $M$ & $S E$ & Error Rate \\
\hline No distractor & 710 & 16 & 9.7 \\
Begin-related distractor & 767 & 15 & 9.1 \\
Unrelated distractor & 796 & 15 & 9.3 \\
\hline
\end{tabular}


of the items. For 15 out of 60 items, the rate of valid observations was less than $33 \%$ (corresponding to six observations) in one or more conditions. Thus, omitting the familiarization and practice led to an increase in the rates of naming errors and spoiled trials, but it did not change the overall pattern of results obtained for the valid naming latencies. Indeed, response times were accelerated in the related relative to the unrelated condition by $3.1 \%, 2.7 \%$, and $3.6 \%$ in Experiments 2A, 2B, and 3, respectively.

The analysis including the three presentations of the materials as a variable yielded a main effect of presentation $\left[F(2,34)=8.12, M S_{\mathrm{e}}=5,874, p<.01\right]$, with the naming latencies decreasing across the three presentations of the materials (means: $792 \mathrm{msec}, 763 \mathrm{msec}$, and $731 \mathrm{msec}$ ). The main effect of distractor condition was also significant $\left[F(2,34)=77.13, M S_{\mathrm{e}}=1,326, p<.001\right]$, as was the interaction of presentation and distractor condition $\left[F(2,34)=5.17, M S_{\mathrm{e}}=1,017, p<.01\right]$. The difference between the unrelated and the no-distractor condition was substantial and highly significant $(p<.001)$ for each presentation of the targets $(72,84$, and 99 msec for the first, second, and third presentations, respectively). The latency difference between the begin-related and unrelated conditions was $48 \mathrm{msec}$ for the first presentation $[t(17)=4.32$, $p<.001], 27 \mathrm{msec}$ for the second presentation $[t(17)=$ $2.19, p<.01]$, and only $7 \mathrm{msec}$, and not significant, for the third presentation.

Contrary to what one might expect, the size of the relatedness effect appeared to decrease across the repetitions of the materials. However, in an ANOVA including only the related and unrelated conditions, the interaction of relatedness and presentation was not significant $[F(2,34)=$ 1.99]. It should be recalled that in Experiments 2A and $2 \mathrm{~B}$, there was also some variation in the strength of the relatedness effects seen for the three presentations of the materials. In each experiment, the relatedness effect was significant for two of the three presentations of the materials, and very small, and not significant, in one presentation. This was the second presentation in Experiment 2A, the first in Experiment 2B, and the third in Experiment 2C. Taken together, these results do not suggest that the size of the relatedness effect systematically increased or decreased over the repetitions of the materials.

\section{GENERAL DISCUSSION}

In all three of the experiments reported above, the mean target-naming latencies were shorter when the names of the targets and distractors were phonologically related than when they were unrelated. This replicates an important finding of the studies by Morsella and Miozzo (2002) and Navarrete and Costa (2005). The effect of begin-related distractors, in comparison with unrelated ones, was very similar in size in all studies: $21 \mathrm{msec}$ in Morsella and Miozzo's experiment, $24 \mathrm{msec}$ in Navarrete and Costa's experiment, and $23 \mathrm{msec}$ in Experiment 2A. The phonological relatedness effect demonstrates that while speakers are planning the name of a target picture, the name of a distractor picture that is simultaneously presented in the same location can become activated as well.

The present study is the first one to examine the effects of different types of phonological relatedness (homophony and begin- and end-relatedness) between targets and distractors. The homophonous distractors yielded a slightly larger relatedness effect $(39 \mathrm{msec})$ than the beginrelated distractors (23 msec, Experiment 2A) and the endrelated ones $(21 \mathrm{msec})$, either because the homophonous distractors shared all, rather than some, segments with the targets, or because only the homophonous distractors, but not the related ones, shared the morphological representation with the targets. The similarity of the results obtained for begin-related and end-related distractors provides some information about the likely origin of the facilitatory effect: It suggests that the effect, like the phonological relatedness effect observed in the picture-word interference paradigm (e.g., Meyer \& Schriefers, 1991), arises at the phonological level, rather than during the selection of articulatory commands. When participants view a targetdistractor composite, both objects are recognized, and the associated lemmas and morphological and phonological forms become activated. When the two object names are phonologically similar, some of the target segments receive activation from the distractor, which allows them to be selected slightly earlier than when the distractor is unrelated and does not activate any target segments. If the effect arose later, during the selection of the articulatory commands, one would expect to see an effect only in the begin-related, but not in the end-related, condition. This is because there is good evidence that speakers can select the articulatory commands for the initial part of a word without knowledge of the final part, but that they cannot select the articulatory commands in reversed order (e.g., Cholin et al., 2004; Meyer, 1990, 1991; Roelofs, 2004).

A second novel feature of the present experiments was that they demonstrated that the phonological relatedness effect could be obtained in the presence as well as in the absence of a familiarization and training phase, and that the size of the effect did not develop systematically across the repetitions of the materials. Apparently, the names of distractor pictures become available quite readily, even when speakers have not seen or named the objects frequently before. This is perhaps shown most clearly in Experiment 3 , in which the participants were not familiarized with the materials and in which a strong relatedness effect was seen for the first presentation of the materials.

In the present experiments, each object was used as a target and as a distractor. One may ask whether this is necessary for obtaining the phonological relatedness effect. Perhaps the name of a distractor becomes activated only after it has been named on an earlier trial or when participants realize that the distractors are targets on other trials and that the distractor names are potential responses. However, in the picture-picture interference experiments carried out by Morsella and Miozzo (2002) and Navarrete and Costa (2005), the distractors were not used as targets, yet reliable phonological relatedness effects were seen. In addition, Navarrete and Costa carried out experiments 
in which the participants, who were native speakers of Spanish, saw line drawings and had to name the color in which they were drawn, or the color of a patch that was embedded within the line drawing. The color name and object name were phonologically related, as in verde ("green")-vela ("candle"), or unrelated, as in verde-nariz ("nose"). The distractors (the names of the objects) and the responses belonged to different syntactic categories (nouns vs. adjectives), and the distractor names were not plausible responses. Nevertheless, the mean color-naming latency was shorter in the phonologically related than in the unrelated condition.

Our experiments, as well as those reported by Morsella and Miozzo (2002) and by Navarrete and Costa (2005), yielded small but reliable phonological priming effects. These findings contrast with those reported by La Heij and colleagues (Bloem \& La Heij, 2003; Bloem et al., 2004; La Heij et al., 1996), who used a translation task to elicit the target words. As described in the introduction, semantically related distractor pictures yielded facilitation in comparison with unrelated pictures, whereas phonologically related distractors yielded no effect.

Further research is necessary to determine why the names of distractor pictures become readily available when other pictures are named, but apparently not when words are translated. Navarrete and Costa suggested that the translation task might be more difficult, and that the distractor picture might therefore be processed less extensively in the translation than in the latter picture-naming task. The absence of a phonological effect in the translation experiments might also be related to the fact that the participants carried out a bilingual task. Since they read English words, the English names of the distractor pictures may have become highly activated in addition to the Dutch names. Perhaps there was no phonological relatedness effect because the distractor picture activated several names, only one of which was phonologically related to the Dutch response word. Costa, Caramazza, and Sebastián-Gallés (2000; see also Costa, Santesteban, \& Caño, 2005) showed that bilingual speakers named pictures faster when the names in their two languages were phonologically similar than when they were dissimilar. This supports the hypothesis that both names associated with a concept in a bilingual speaker's lexicon can become activated simultaneously.

Another issue for further research concerns the dissociation between the semantic and phonological effects in the picture-picture interference paradigm: Phonologically related distractor pictures facilitate target naming in comparison with unrelated ones, but Damian and Bowers (2002) and Navarrete and Costa (2005) showed that semantically related distractors (i.e., members of the same semantic category as the targets) and unrelated distractors did not differ in their effects. In recent experiments, in which we used the same procedure as in the above experiments, we also failed to obtain a semantic relatedness effect. The dissociation between the semantic and phonological effects is puzzling, because according to most current models of word production, word forms are activated after word meanings (e.g., Caramazza, 1997; Levelt et al., 1999; Rapp \& Goldrick, 2000).

One account for the absence of the semantic relatedness effect is that semantically related distractor pictures facilitate the recognition of the targets, but interfere with the retrieval of their names, and that these effects cancel each other (Navarrete \& Costa, 2005; see also Bloem \& La Heij, 2003). Alternatively, there might not be a strong semantic effect at any level. Belke, Meyer, and Damian (2005) used a semantic blocking paradigm, in which speakers repeatedly named sets of objects, which either belonged to the same semantic category (e.g., duck, snake, mouse, horse) or to different categories (duck, chair, vest, car; see also Kroll \& Stewart, 1994). The object-naming latencies were longer in semantically homogeneous than in heterogeneous blocks, but, importantly, this blocking effect was observed only after the speakers had named the objects several times. Belke et al. (2005) proposed that members of the same semantic category activate each other through their links to a joint category node (e.g., animal). However, the activation flow between the category members and the superordinate node is not strong, and measurable mutual activation and competition between members of the same category arise only if the category node is accessed repeatedly within a short time period. This is obviously not the case in the picture-picture interference paradigm, in which participants see members of different semantic categories on each trial.

The general theoretical question motivating the present research was whether every concept that is activated in a speaker's mind automatically activates the corresponding name in the mental lexicon, or whether name activation is restricted in some way. On the basis of the present data and related recent evidence, we adopt the former view: There is no strict boundary between the conceptual and the lexical network, and any activated concept passes part of its activation on to the associated lexical units. However, the activation of concepts and lexical units will often be too weak or too short-lived to have any behavioral consequences. A minimal requirement for any measurable activation of the name of an object is probably that the object is recognized - that is, that a unique structural representation is selected. On most theories, this presupposes that the viewer allocates some visual attention to the object (e.g., Germeys, de Graef, \& Verfaillie, 2002; Henderson \& Hollingworth, 2003; Henderson \& Siefert, 1999; Rensink, 2000). A complex object that is only viewed extrafoveally and is not attended to will usually not activate any visual or conceptual representation strongly enough for object recognition to occur, and one would not expect the name of such an object to be activated. By contrast, an object that is attended to might be recognized, and activation should then be passed on from the conceptual to the lexical representations. Whether this leads to measurable effects in psycholinguistic tasks will probably depend, among other things, on the dynamics of the speaker's allocation of visual attention: The longer an object remains in the focus of visual attention, the more likely it should be that the object will activate its name. In addition, properties of the objects (e.g., their familiar- 
ity to the viewer) and their names (such as age of acquisition, length, and frequency) should also affect how readily their names become available (Humphreys \& Forde, 2001; Morgan \& Meyer, 2005). Obviously, further research is required to determine the conditions for the activation of lexical knowledge associated with conceptual representations. The experiments described here demonstrated that under some conditions, the names of objects that speakers do not intend to refer to become activated, as predicted by cascaded models of lexical access.

\section{AUTHOR NOTE}

This research was supported by Nuffield Foundation Social Sciences Small Grant SGS/00912/G to A.S.M. and M.F.D. The authors thank Christine Häcker, Alicja Polednia, Rohini Sirpal, and Alana Tooze for running the experiments. Correspondence concerning this article should be addressed to A. S. Meyer, School of Psychology, University of Birmingham, Edgbaston, Birmingham B15 2TT, England (e-mail: a.s.meyer@bham.ac.uk).

\section{REFERENCES}

Belke, A. S., Meyer, A. S., \& Damian, M. (2005). Refractoriness in the semantic system. Quarterly Journal of Experimental Psychology, 58, 667-692.

Bloem, I., \& La HeIJ, W. (2003). Semantic facilitation and semantic interference in word translation: Implications for models of lexical access in language production. Journal of Memory \& Language, 48, 468-488.

Bloem, I., van den Boogard, S., \& La HeiJ, W. (2004). Semantic facilitation and semantic interference in language production: Further evidence for the conceptual selection model of lexical access. Journal of Memory \& Language, 51, 307-323.

Brown, R., \& MCNeILL, D. (1966). The "tip-of-the-tongue" phenomenon. Journal of Verbal Learning \& Verbal Behavior, 5, 325-337.

Butterworth, B. (1989). Lexical access in speech production. In W. Marslen-Wilson (Ed.), Lexical representations and process (pp. 108-135). Cambridge, MA: MIT Press.

Caramazza, A. (1997). How many levels of processing are there in lexical access? Cognitive Neuropsychology, 14, 177-208.

Caramazza, A., Bi, Y. C., Costa, A., \& Miozzo, M. (2004). What determines the speed of lexical access: Homophone or specific-word frequency? A reply to Jescheniak et al. (2003). Journal of Experimental Psychology: Learning, Memory, \& Cognition, 30, 278-282.

Caramazza, A., Costa, A., Miozzo, M., \& BI, Y. (2001). The specificword frequency effect: Implications for the representation of homophones in speech production. Journal of Experimental Psychology: Learning, Memory, \& Cognition, 27, 1430-1450.

Cholin, J., Schiller, N. O., \& Levelt, W. J. M. (2004). The preparation of syllables in speech production. Journal of Memory \& Language, 50, 47-61.

Collins, A. F., \& Ellis, A. W. (1992). Phonological priming of lexical retrieval in speech production. British Journal of Psychology, 83, 375-388.

Costa, A., Caramazza, A., \& Sebastián-Gallés, N. (2000). The cognate facilitation effect: Implications for models of lexical access. Journal of Experimental Psychology: Learning, Memory, \& Cognition, 26, 1283-1296.

Costa, A., Santesteban, M., \& Caño, A. (2005). On the facilitatory effects of cognate words in bilingual speech production. Brain \& Language, 94, 94-103.

DAMIAN, M. F., \& Bowers, J. S. (2003). Locus of semantic interference in picture-word interference tasks. Psychonomic Bulletin \& Review, 10, 111-117.

Damian, M. F., \& Martin, R. C. (1999). Semantic and phonological codes interact in single word production. Journal of Experimental Psychology: Learning, Memory, \& Cognition, 25, 345-361.

Dell, G. S. (1986). A spreading-activation theory of retrieval in sentence production. Psychological Review, 93, 283-321.

Dell, G. S., Burger, L. K., \& Svec, W. R. (1997). Language produc- tion and serial order: A functional analysis and a model. Psychological Review, 104, 123-147.

Dell, G. S., \& ReICH, P. A. (1981). Stages in sentence production: An analysis of speech error data. Journal of Verbal Learning \& Verbal Behavior, 20, 611-629.

Ferreira, V. S., \& Griffin, Z. M. (2003). Phonological influences on lexical (mis)selection. Psychological Science, 14, 86-90.

FodOR, J. A. (1983). The modularity of mind. Cambridge, MA: MIT Press.

GARRETT, M. F. (1980). Levels of processing in sentence production. In B. Butterworth (Ed.), Language production (pp. 177-230). New York: Academic Press.

Germeys, F., De Graef, P., \& Verfaillie, K. (2002). Transsaccadic perception of saccade target and flanker objects. Journal of Experimental Psychology: Human Perception \& Performance, 28, 868-883.

Henderson, J. M., \& Hollingworth, A. (2003). Eye movements and visual memory: Detecting changes to saccade targets in scenes. Perception \& Psychophysics, 65, 58-71.

Henderson, J. M., \& Siefert, A. B. C. (1999). The influence of enantiomorphic transformation on transsaccadic object integration. Journal of Experimental Psychology: Human Perception \& Performance, 25, 243-255.

Humphreys, G. W., \& Forde, E. M. E. (2001). Hierarchies, similarity, and interactivity in object recognition: "Category-specific" neuropsychological deficits. Behavioral \& Brain Sciences, 24, 453-509.

Humphreys, G. W., Riddoch, M. J., \& Quinlan, P. T. (1988). Cascade processes in picture identification. Cognitive Neuropsychology, 5, 67-103.

Jescheniak, J. D., Hahne, A., \& Schriefers, H. (2003). Information flow in the mental lexicon during speech planning: Evidence from event-related brain potentials. Cognitive Brain Research, 15, 261-276.

Jescheniak, J. D., \& Levelt, W. J. M. (1994). Word frequency effects in speech production: Retrieval of syntactic information and of phonological form. Journal of Experimental Psychology: Learning, Memory, \& Cognition, 20, 824-843.

Jescheniak, J. D., Meyer, A. S., \& Levelt, W. J. M. (2003). Specificword frequency is not all that counts in speech production: Comments on Caramazza, Costa et al. and new experimental data. Journal of Experimental Psychology: Learning, Memory, \& Cognition, 29, 432-438.

JESCHENIAK, J. D., \& SCHRIEFERs, H. (1998). Discrete serial versus cascaded processing in lexical access in speech production: Further evidence from the coactivation of near-synonyms. Journal of Experimental Psychology: Learning, Memory, \& Cognition, 24, 1256-1273.

Kroll, J. F., \& Stewart, E. (1994). Category interference in translation and picture naming: Evidence for asymmetric connections between bilingual memory representations. Journal of Memory \& Language, 13, 149-174.

La Heis, W., Hooglander, A., Kerling, R., \& van der Velden, E. (1996). Nonverbal context effects in forward and backward word translation: Evidence for conceptual mediation. Journal of Memory \& Language, 35, 648-665.

LEVELT, W. J. M. (1989). Speaking: From intention to articulation. Cambridge, MA: MIT Press.

Levelt, W. J. M. (1999). Models of word production. Trends in Cognitive Sciences, 3, 223-232.

Levelt, W. J. M., Roelofs, A., \& Meyer, A. S. (1999). A theory of lexical access in speech production. Behavioral \& Brain Sciences, 22, 1-38.

Levelt, W. J. M., Schriefers, H., Vorberg, D., Meyer, A. S., Pechmann, T., \& Havinga, J. (1991). The time course of lexical access in speech production: A study of picture naming. Psychological Review, 98, 122-142.

MacKaY, D. G. (1987). The organization of perception and action: A theory for language and other cognitive skills. New York: Springer.

Meyer, A. S. (1990). The time course of phonological encoding in language production: The encoding of successive syllables. Journal of Memory \& Language, 29, 524-545.

Meyer, A. S. (1991). The time course of phonological encoding in language production: Phonological encoding inside a syllable. Journal of Memory \& Language, 30, 69-89.

Meyer, A. S., \& BeLKe, E. (in press). Word form retrieval in language 
production. In G. Gaskell (Ed.), Oxford Handbook of Psycholinguistics. Oxford: Oxford University Press.

Meyer, A. S., \& Schriefers, H. (1991). Phonological facilitation in picture-word interference experiments: Effects of stimulus onset asynchrony and types of interfering stimuli. Journal of Experimental Psychology: Learning, Memory, \& Cognition, 17, 1146-1160.

Miozzo, M., JACoBs, M. L., \& Singer, N. J. W. (2004). The representation of homophones: Evidence from anomia. Cognitive Neuropsychology, 21, 840-866.

Morgan, J. L., \& Meyer, A. S. (2005). Processing of extrafoveal objects during multiple object naming. Journal of Experimental Psychology: Language, Memory, \& Cognition, 31, 428-442.

Morsella, E., \& Miozzo, M. (2002). Evidence for a cascade model of lexical access in speech production. Journal of Experimental Psychology: Learning, Memory, \& Cognition, 28, 555-563.

NaVArRete, E., \& Costa, A. (2005). Phonological activation of ignored pictures: Further evidence for a cascade model of lexical access. Journal of Memory \& Language, 53, 359-377.

Peterson, R. R., \& Savoy, P. (1998). Lexical selection and phonological encoding during language production: Evidence for cascaded processing. Journal of Experimental Psychology: Learning, Memory, \& Cognition, 24, 539-557.

RAPP, B., \& GOLDRICK, M. (2000). Discreteness and interactivity in spoken word production. Psychological Review, 107, 460-499.

RatcLiff, R. (1993). Methods for dealing with reaction time outliers. Psychological Bulletin, 114, 510-532.

Rensink, R. A. (2000). Seeing, sensing, and scrutinizing. Vision Research, 40, 1469-1487.

Roelofs, A. (1992). A spreading-activation theory of lemma retrieval in speaking. Cognition, 42, 107-142.

RoELOFs, A. (1997). The WEAVER model of word-form encoding in speech production. Cognition, 64, 249-284.

RoELOFS, A. (2002). Spoken language planning and the initiation of articulation. Quarterly Journal of Experimental Psychology, 55A, 465-483.
Roelofs, A. (2004). Seriality of phonological encoding in naming objects and reading their names. Memory \& Cognition, 32, 212-222.

Schriefers, H., Meyer, A. S., \& Levelt, W. J. M. (1990). Exploring the time course of lexical access in language production: Picture-word interference studies. Journal of Memory \& Language, 29, 86-102.

Sevald, C. A., \& Dell, G. S. (1994). The sequential cuing effect in speech production. Cognition, 53, 91-127.

SNODGRASS, J. G., \& VANDERWART, M. (1980). A standardized set of 260 pictures: Norms for name agreement, image agreement, familiarity, and visual complexity. Journal of Experimental Psychology: Human Learning \& Memory, 6, 174-215.

Stemberger, J. P. (1985). An interactive activation model of language production. In A. W. Ellis (Ed.), Progress in the psychology of language (Vol. 1, pp. 143-186). Hillsdale, NJ: Erlbaum.

VAN Selst, M., \& Jolicceur, P. (1994). A solution to the effect of sample size on outlier elimination. Quarterly Journal of Experimental Psychology, 47A, 631-650.

Vigliocco, G., Antonini, T., \& Garrett, M. F. (1997). Grammatical gender is on the tip of Italian tongues. Psychological Science, $\mathbf{8}$, 314-317.

Wilshire, C. E., \& Saffran, E. M. (2005). Contrasting effects of phonological priming in aphasic word production. Cognition, 95, 31-71.

\section{NOTES}

1. A listing of the materials can be obtained from the corresponding author.

2. Since only a third of the items were tested in each condition in each block, a by-item analysis was not feasible.

(Manuscript received May 16, 2005; revision accepted for publication January 24,2006 .) 